\title{
Special COVID-19 Issue
}

\author{
Norman E. Taylor*
}

Welcome to our special COVID-19 issue of the Journal of Community Safety and Well-Being. We recognized early in the pandemic that there would be much for everyone to learn, and we hoped that, among the scholars, policy-makers, and practitioners that comprise our journal community, we might find some willing to contribute to this global learning, even as they were adapting daily to new challenges at home and at work. The response has exceeded our expectations, and this special issue is our largest to date, by far.

I would like to extend my appreciation to the many authors who have contributed with thoughtful and urgently relevant content, and to our Section and Contributing Editors and all of our Reviewers who helped us to complete the publication cycle in record time while maintaining high editorial standards.

I also want to acknowledge the incredible team at SG Publishing. Not only have they moved double our usual number of papers through to readiness during difficult personal times, they have also planned, designed and executed our transition to a whole new look and functionality for our Journal site. Our OJS 3 upgrade officially launches today in conjunction with this special issue.

The COVID crisis is far from over, and I can assure you the Journal will continue to feature relevant pandemic material in subsequent issues, even as other critical, emerging social priorities continue to form before our eyes. In the meantime, I encourage our Readers to dig deep into the 15 articles that comprise this issue.

Thanks to all of you for contributing to this vital CSWB dialogue in challenging times. Our open call for papers continues.

\section{CONFLICT OF INTEREST DISCLOSURES}

The author has continuing business interests that include providing advisory services to communities, police services and related human service agencies.

AUTHOR AFFILIATIONS

*Editor-in-Chief, Journal of Community Safety and Well-Being 